Sergey Elagin

Peoples' Friendship University of Russia, Moscow

\title{
Development of industrial areas on the territory of Moscow and their reorganization at the turn of the 21 st century
}

The city's territory is more than $1000 \mathrm{sq} . \mathrm{km}$ (from north to south - more than $40 \mathrm{~km}$, from west to east - more than $30 \mathrm{~km}$ ), the city's population is more than 10 million people. More than 50 industrial areas and territories are situated in the city, while more than $30 \%$ of the city's territory is taken by forest and parkland zones.

The main factor of locating manufactories, factories and plants at the end of 17 th and beginning of 18th century was the availability of energy sources in the form of water mills. The first territories where the groups of manufacturing facilities were built were situated by the riverbank of the Moscow river and its feeders - Yauza, Neglinnaya and Presnya rivers (Fig. 1).

The second stage of building industrial areas (zones) on the territory of the Moscow city is connected with development of railroads during the period of 1860s-1880s. The production facilities began to be constructed near the trunk railway lines, as they enabled the transportation of raw materials and fuel from other regions of the Russian empire, as well as transportation of the end products to the regions of their consumption throughout the country.

The next stage of creating large industrial zones in Moscow was connected with the process of industrialization of the 1920s-1930s and with the postwar recovery of the country's economy. At that period, the basis of industrial areas formation was the building of powerelectricity-generating objects (thermal power plants - TPP).

As a result of changes in political and economical foundations of governmental life of the country at the end of the $20^{\text {th }}$ century, together with reorganization of economy "from plan to market" the process of changes in the industrial sphere began in the Moscow city. Privatization of enterprises was carried out. They were undergoing restructuring and liquidation. A spontaneous process of wide-scale building of commercial residential housing estates and shopping centres began in the city (the city land became an object of sale).

In such circumstances the Moscow Government began the regulation policy of this process on the territory of the city. The main directions of reorganization of industrial zones have been drawn out by the Moscow Committee of Architecture. Regulatory and legislative decisions have been made on different approaches to industrial zones, first by the Government of the city and then by the Moscow City Duma as well (Fig. 2). 


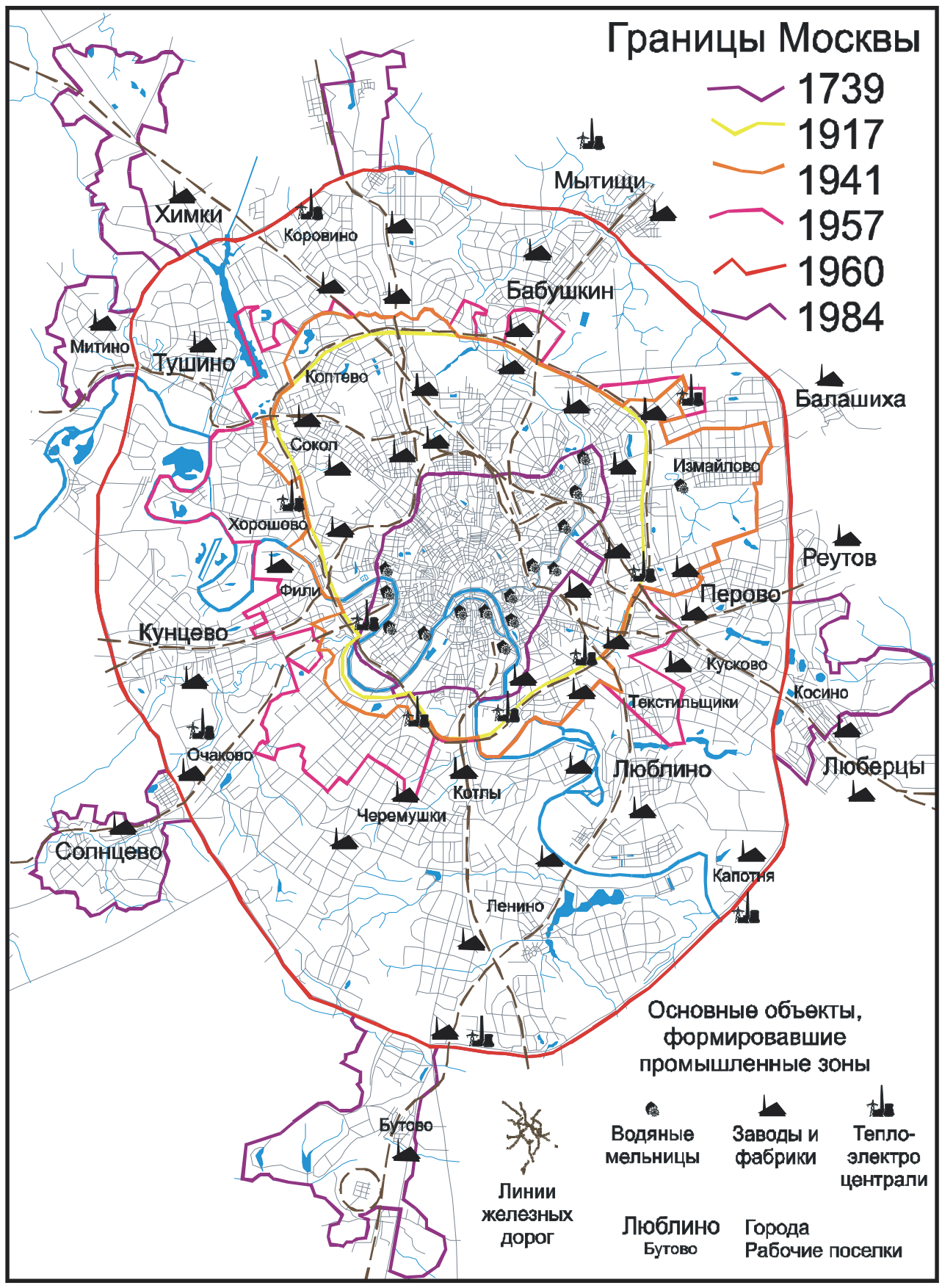

Fig. 1. Development of industrial zones on the territory of Moscow 


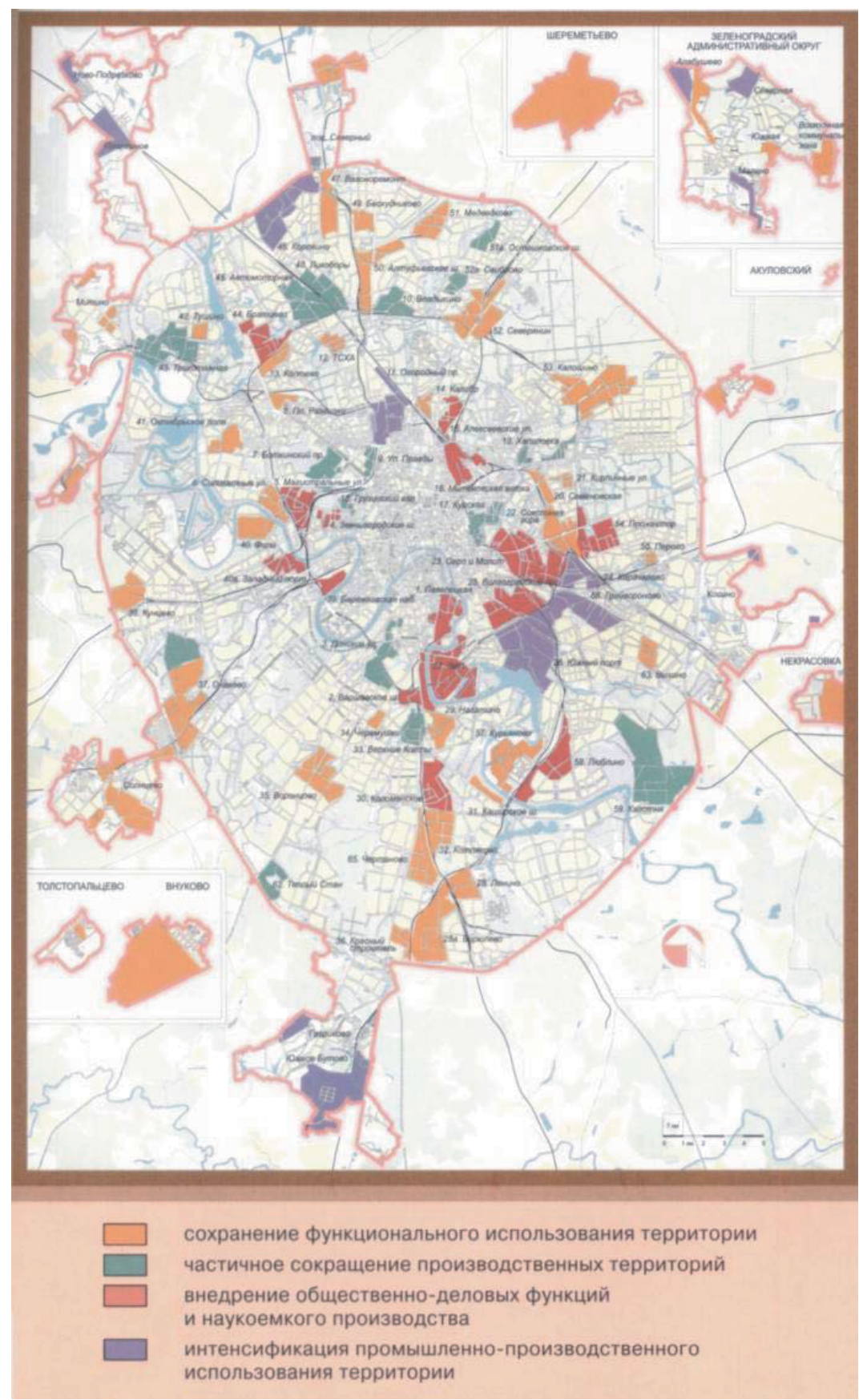

Fig. 2. Main urban-planning reorganization concepts of industrial zones of Moscow

Source: "Contemporary Moscow: City map". Informative and reference edition., JSV “Atlas-Print”, 2004. Moscow. Sources and materials of Moscow Government: http://www.mos.ru. 
It has been decided that it is necessary to leave a part of the territories as industrial area, another part is to be reduced or liquidated, and another part is planned to be reorganized. At present, the process of reorganization is completed in some territories, in some territories it is under way, in others - documentation necessary for various projects is still being prepared.

Under the condition of establishment of market institutions, the process of effective usage of the city territory as an aim of reorganization of industrial zones has a progressive nature. Nevertheless, along with reorganizing, liquidation or moving of the production units to other regions take place. It is happening not only with units of conventional branches of heavy industry that pollutes the environment, but also with machinery plants and experimental productions. In our opinion that is not quite correct.

The examples of reorganization of some industrial zones of the Moscow City are given below. In a number of cases the territory changes its functional meaning when the production entities are liquidated. In other cases production entities only change the profile of their activity. The third alternative is when the territory of industrial zones is reduced.

Fig. 3 and 4 show the examples of industrial zones reorganization in the central historical part of the city.

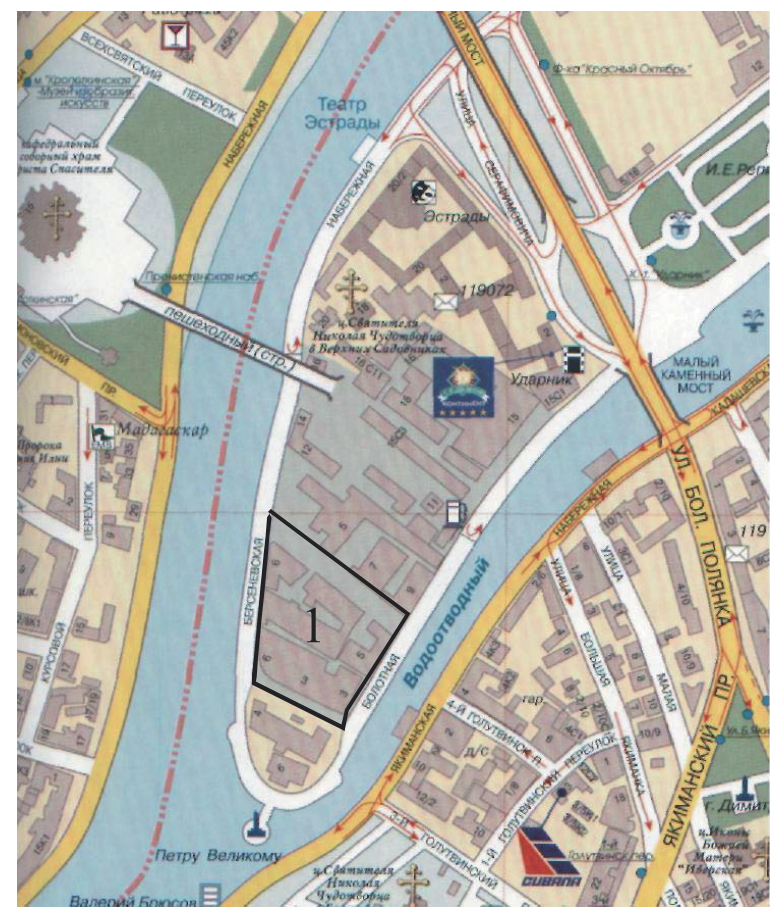

Fig. 3. Western part of the "island" and confectionary plant (plant territory is marked by number 1 on the map) 


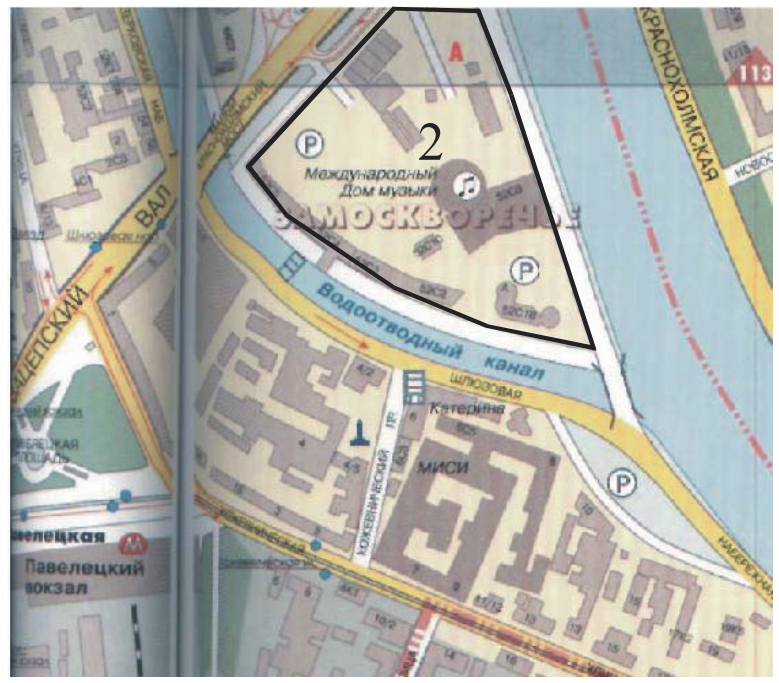

Fig. 4. Eastern part of the "island" and industrial area (marked by number 2 on the map)

At the turn of the 21 st century, in the eastern part of the "island", in Zamoskvorech'e, on the territory of former factories, warehouses and production bases, a large metropolis/ community and business centre "Krasnye holmy" was created, which includes concert halls, theatrical stages, hotel, business offices and also an underground parking lot. In the western part of the "island", opposite to the Cathedral of Christ the Savior, on the former territory of production premises of the confectionary plant "Krasny Oktyabyr", TPP-2 and ware houses zone, a hotel centre and recreation areas are now being constructed, and under the water channel a large parking lot is planned to be created.

Fig. 5 and 6 show examples of construction of residential quarters and also trade and service sector enterprises on the territories of former brickyards.

One more example of industrial zone liquidation is shown in Fig. 7

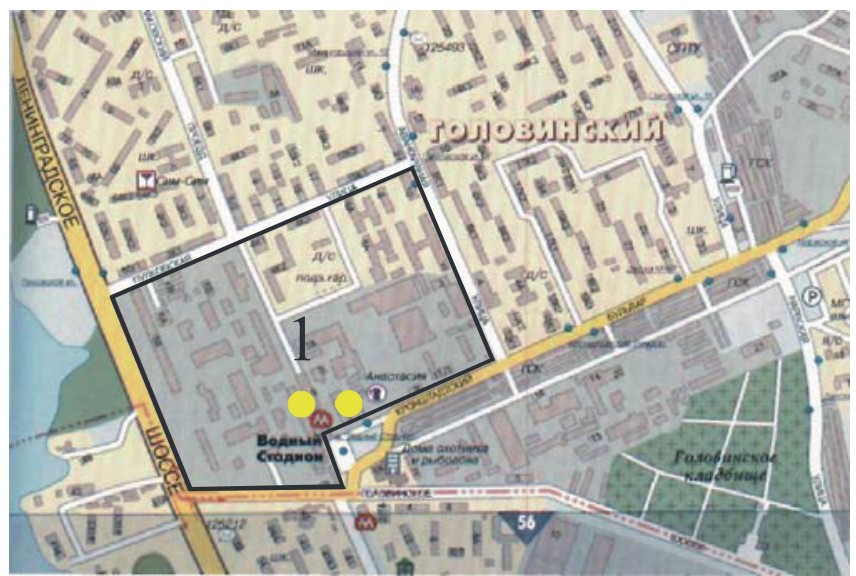

Fig. 5. Building development on the territories of former Nikolskiy brickyards (marked by number 1 on the map) 


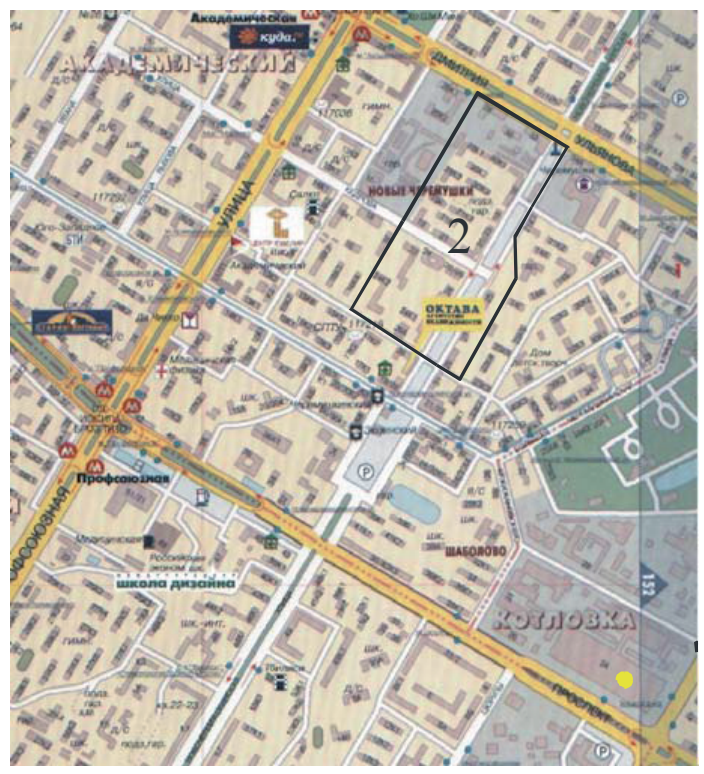

Fig. 6. Building development on the territories of former Cheremushkinsky brickyards (marked by number 2 on the map)

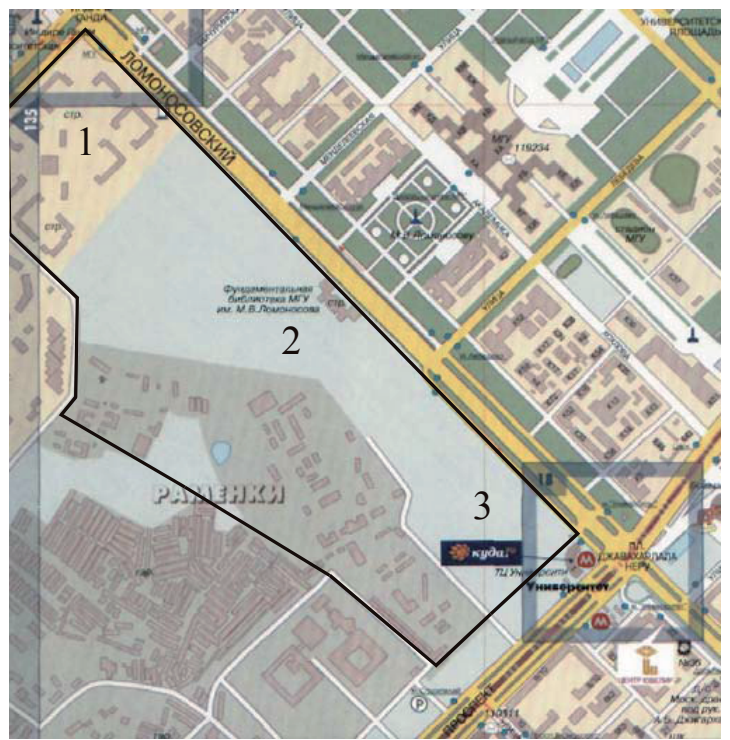

Fig. 7. Building development on the former territories of construction companies (residential quarters marked by numbers 1 and 3, faculties' buildings of Moscow State University - by 2)

Residential quarters (along Michurinsky av. and near metro station "Universitet") and also buildings of scientific research organizations (along Vernadsky prospect) are being build nowadays on the territory of construction profile entities that remained after the construction of group of buildings of Lomonosov Moscow State University at Leninskie 
Gory in 1950s-1960s. Moreover, at present, new buildings are being constructed for various faculties of Lomonosov Moscow State University (for example, around the new building of Lomonosov Moscow State University's library), to the south-west from which a parking area will be created.

Examples of production premises reprofiling are shown in Figures 8, 9 and 10, and an example of production territory reduction - in Figures 11 and 12.

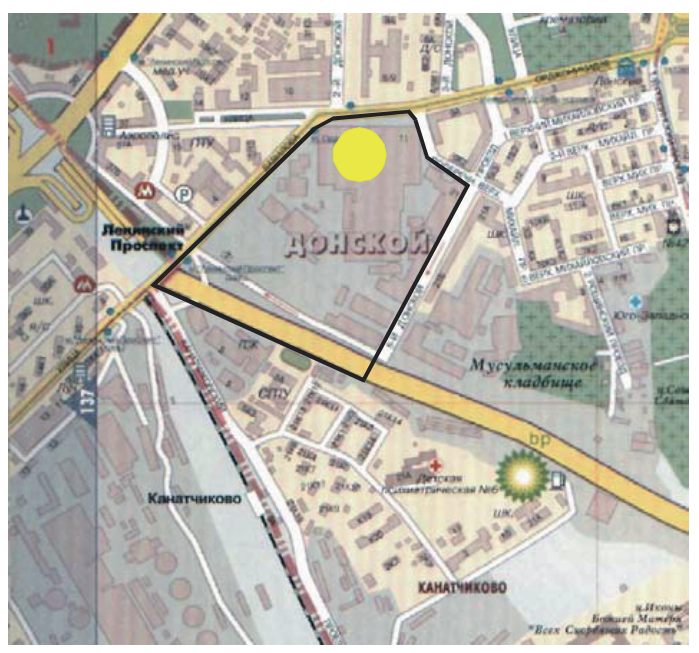

Fig. 8. Liquidation of Ordjonikidze machine-tool plant and opening

Therefore a conclusion can be made that the implementation of the plan on transformation of existent industrial areas is being carried out at full speed in Moscow. In a number of cases it is reasonable and favorable for the city and its population. In a number of other cases, however, detailed research and decision making are required on the state level.

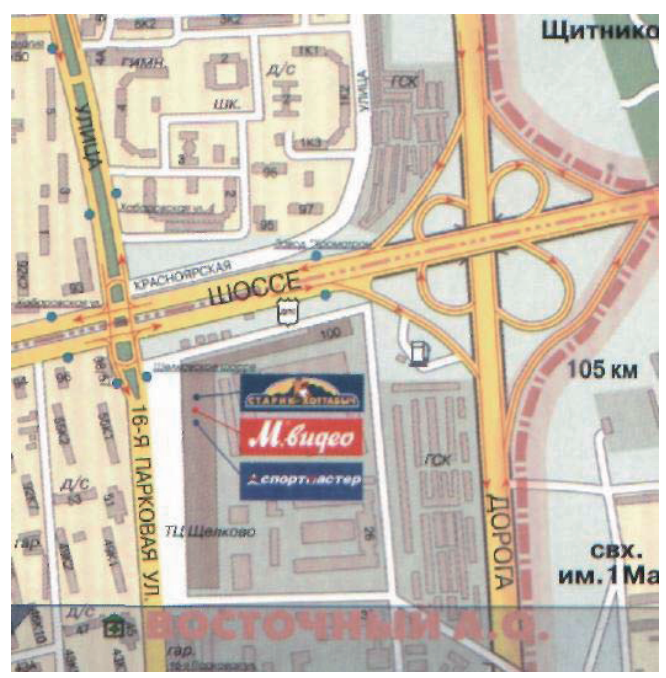

Fig. 9. Construction of a trade center on the territory of former scientific research institute 


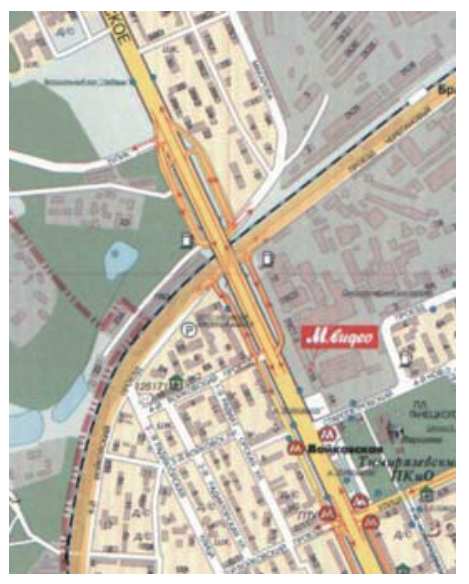

Fig. 10. Construction of a trade center on the territory of former industrial area

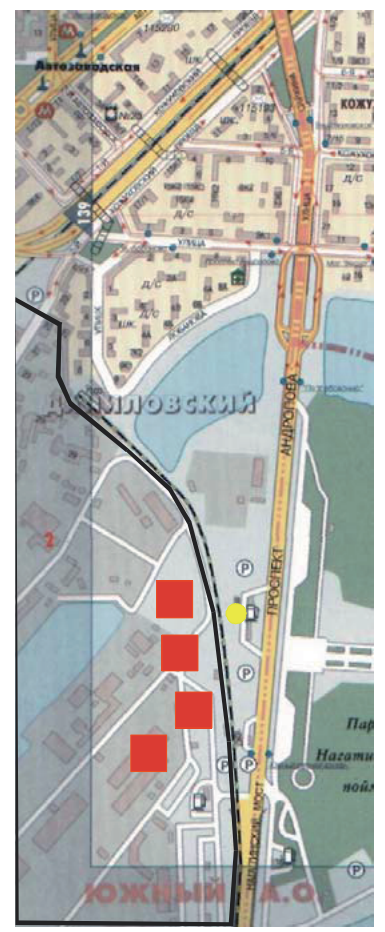

Fig. 11. Production territory reduction of territories of Likhachev automobile plant (ZIL) and construction of business centers 


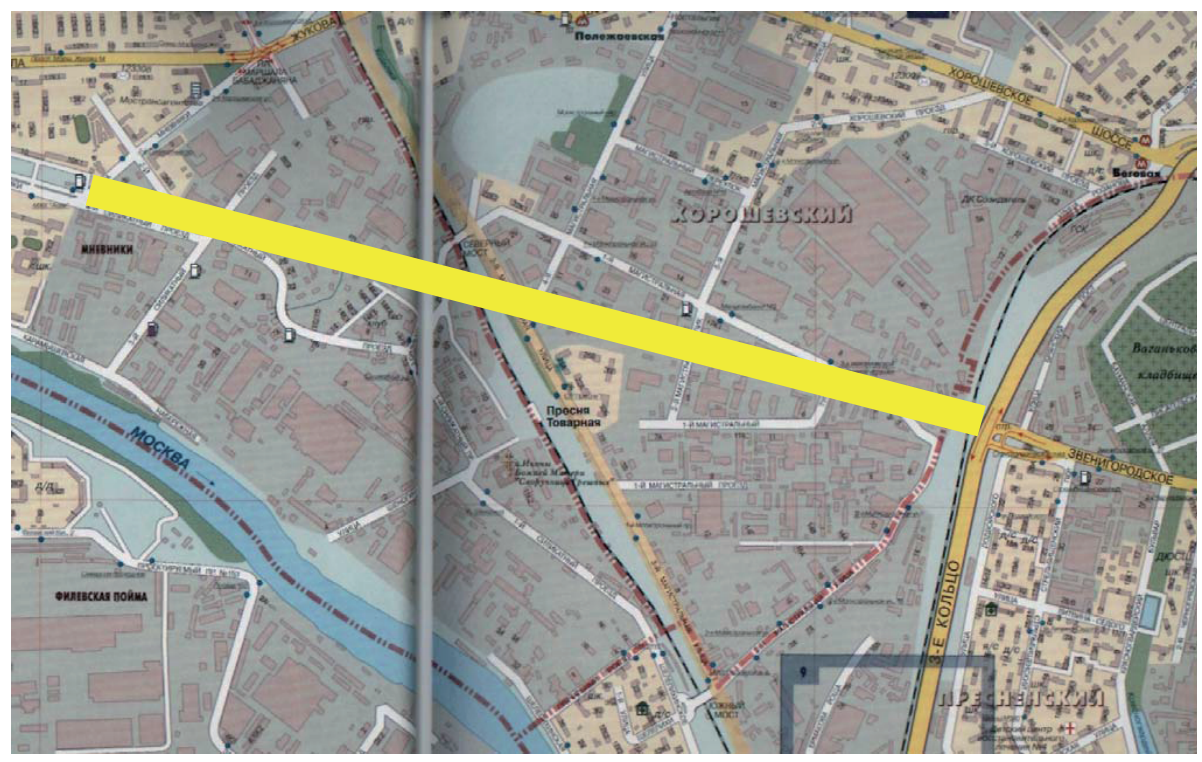

Fig. 12. Industrial area reduction due to elevated highway construction

- the new radial highway of Krasnopresnensky prospect

\section{Development of industrial areas on the territory of Moscow and their reorganization at the turn of the $21^{\text {st }}$ century}

The article outlines the main features of the development of industrial areas (zones) on the territory of Moscow and their reorganization in the period 1990-2009. Along with the reorganization of economy "from plan to market", the process of changes in the industrial sphere began in Moscow City. It is noted that during that period privatization of many industrial enterprises was carried out. They were undergoing restructuring and liquidation. A spontaneous process of wide-scale building of commercial housing estates and shopping centres began in Moscow City on the former territories of production facilities. Pictures No. 1-11 show the examples of industrial zones reorganization in the city.

\section{Sergey Elagin}

Peoples' Friendship University of Russia, Moscow

Faculty of Economics

Department of Regional Economy and Geography

e-mail: selagin@yandex.ru 